\title{
Cerebellar degeneration in neuroleptic malignant syndrome: neuropathologic findings and review of the literature concerning heat-related nervous system
} injury

\author{
S LEE,* A MERRIAM, $\dagger$ T-S KIM,* M LIEBLING,* D W DICKSON,* G R W MOORE* \\ From the Department of Pathology (Neuropathology) and the Rose F Kennedy Center for Research in Mental \\ Retardation and Human Development, ${ }^{*}$ and the Departments of Psychiatry and Neurology, $\dagger$ Albert Einstein \\ College of Medicine, Bronx, New York, USA
}

SUMMARY A selective subtotal cerebellar neuronal degeneration was found in a patient who died $4 \frac{1}{2}$ months after suffering neuroleptic malignant syndrome (NMS), a rare, potentially fatal disorder associated with neuroleptic medications. It is suggested that the cerebellar neuronal degeneration in this case was due to hyperpyrexia, a cardinal clinical feature of NMS. Similar pathologic findings appear not to have been previously reported in NMS but have been described in heat-induced central nervous system (CNS) injury. The findings imply that a cerebellar syndrome might be encountered in patients who survive NMS complicated by a particularly high febrile course.

Neuroleptic malignant syndrome (NMS) is a potentially lethal reaction to central dopamine blocking agents. ${ }^{1}$ It is characterised clinically by hyperpyrexia, extrapyramidal rigidity, autonomic dysfunction, and depressed sensorium. Elevation of serum creatinine kinase (CK) secondary to rhabdomyolysis, abnormal liver function tests, and leukocytosis are common accompaniments. The disorder is rare, with an estimated incidence of 0.4 to $1.4 \%$, and carries a fatality rate of 4 to $22 \%$ in reported series. ${ }^{2}$

The pathogenesis of the disorder remains speculative. The current theory of the pathophysiological mechanism is extreme blockade of dopamine receptors in both the basal ganglia and hypothalamus resulting in extrapyramidal muscle rigidity with thermogenesis and in impaired central temperature regulation, respectively. ${ }^{2}$ Based on clinical similarities of NMS to malignant hyperthermia (MH), an alternative hypothesis proposes that

Address for reprint requests: Dennis W Dickson, MD, Department of Pathology (Neuropathology), Albert Einstein College of Medicine, 1300 Morris Park Avenue, K-438, Bronx, New York, 10461, USA.

Received 19 August 1988.

Accepted 28 October 1988 neuroleptic medications induce abnormal calcium disposition in the muscle cells of susceptible individuals and thereby trigger muscle rigidity, rhabdomyolysis, and fever. ${ }^{2}$ Observations in biopsy specimens of muscle of NMS survivors that caffeine, ${ }^{3}$ halothane, ${ }^{4}$ and fluphenazine,${ }^{4}$ a neuroleptic, produce abnormal contracture patterns similar to that seen in MH, lends some support to the latter hypothesis.

Despite the voluminous literature on the clinical manifestations and management of NMS, neuropathologic examinations have seldom been reported. The postmortem examination of brain of a patient who developed NMS-like illness after receiving neuroleptics, monoamine oxidase inhibitors, and numerous electroconvulsive treatments, revealed foci of necrosis in the anterior and lateral hypothalamic nuclei. ${ }^{5} \mathrm{~A}$ previous case report by Morris et al revealed no pathologic findings in the brain or muscle of an individual who succumbed to NMS. ${ }^{6}$

The following report describes the neuropathology of a patient who died $4 \frac{1}{2}$ months after an episode of full-blown NMS. We discuss the relationship of cerebellar degeneration to hyperpyrexia which is an invariable component of NMS. A review of the literature confirms the common occurrence of cerebellar injury in other heat-related fatal disorders. 


\section{Case report}

A 32 year old man with Klinefelter's syndrome and chronic schizophrenia was brought to the emergency room with dyspnoea and involuntary dystonic posturing of his limbs. The patient had required multiple psychiatric hospitalisations over the previous 5 years and had been treated with a variety of neuroleptic medications. He had most recently been maintained on haloperidol. Several years previously, he developed involuntary movements of his oral, buccal, lingual, trunk, neck, and limb muscles and tardive dyskinesia was diagnosed. One year prior to admission, in an effort to diminish the dyskinetic movements, he was prescribed the experimental drug tetrabenazine. This was maintained at a dose of $25 \mathrm{mg}$ p.o. four times daily, with an excellent response and without side effects. In the week prior to his presentation he once more sustained an increase in his psychotic symptoms, and his haloperidol dose had accordingly been increased from $10 \mathrm{mg}$ p.o. twice daily to three times daily. The anticholinergic antiparkinsonian agent benztropine was maintained without change at $1 \mathrm{mg}$ p.o. twice daily.

Although on initial presentation to the emergency room the patient was alert and afebrile, he became progressively more rigid and mute over the next several hours as his temperature climbed to $40 \cdot 1^{\circ} \mathrm{C}$. On examination, the patient was tachycardic to 120 beats/min, with a blood pressure of $140 / 90 \mathrm{~mm} \mathrm{Hg}$ and respiration of $36 / \mathrm{min}$. His chest was clear to auscultation and percussion, and his abdomen was soft; he had no lymphadenopathy, skin rash, or other signs of infection. The neurological examination showed him to be initially fully oriented but he soon lapsed into a mute, stuporous state shortly after arrival in the emergency room. His optic discs were flat and the cranial nerve examination showed no abnormalities. He showed continuous dystonic posturing and choreiform movements of all four extremities. Muscle tone was increased, particularly in the lower extremities. The deep tendon reflexes were diffusely hyperactive with sustained ankle clonus. The Babinski sign was absent bilaterally.

The routine admission laboratory studies showed a leukocytosis of $16,200 / \mathrm{mm}^{3}$, with a normal differential. The creatinine kinase was $1,420 \mathrm{U} / \mathrm{L}$ initially and rose to 32,000 $\mathrm{U} / \mathrm{L}$ two days later; $\mathrm{MB}$ fraction was $0 \%$. A chest radiograph was normal. Non-contrast CT of the head was normal. The cerebrospinal fluid was acellular and sterile, with a protein of $26 \mathrm{mg} / 100 \mathrm{ml}$ and a glucose of $91 \mathrm{mg} / 100 \mathrm{ml}$. A diagnosis of neuroleptic malignant syndrome (NMS) was made, and an intravenous infusion of dantrolene $160 \mathrm{mg}$ was administered, along with bromocriptine $2.5 \mathrm{mg}$ by nasogastric tube. The patient responded by exhibiting less muscular hypertonia, by becoming aware of his environment, and by defervescing to $37 \cdot 7^{\circ} \mathrm{C}$.

The following day his muscle rigidity returned and his temperature rose to $38 \cdot 8^{\circ} \mathrm{C}$. Dantrolene was readministered, but the infusion was interrupted after $120 \mathrm{mg}$ was administered when the patient suddenly developed bradycardia (47/ $\mathrm{min}$ ) and hypotension ( $70 \mathrm{mmHg} /$ palpation). He became unresponsive to verbal stimuli, became flaccid, and required mechanical ventilation. An EEG showed diffuse slowing with delta and theta waves, with no lateralising or epileptiform features. Neither dantrolene nor bromocriptine were readministered.
His remaining course was complicated by intercurrent infections with candida, proteus, and klebsiella, and intermittent fever. He showed no major improvement in his mental status throughout the hospitalisation. He failed to respond to his environment. He had no documented episode of clinical hypoxia, until he succumbed of a cardiopulmonary arrest $4 \frac{1}{2}$ months after presentation, and he did not receive anti-convulsant drugs, such as phenytoin.

\section{Pathologic findings}

The general necropsy revealed multiple microabscesses in the kidneys, heart, and gastrointestinal tract. Necrotising abscesses containing mixed bacterial flora were found in the lung, consistent with aspiration pneumonia. No microorganisms were demonstrated in other systemic organs.

\section{Neuropathology}

The brain was unremarkable on inspection. It weighed $1170 \mathrm{~g}$ after fixation in $10 \%$ formaldehyde. No frank haemorrhages or oedema was present. Microscopically, the most striking pathology was in the cerebellum (fig a \& b). There was almost complete loss of Purkinje cells, moderate reduction of granular neurons, and subtotal loss of neurons in the dentate nucleus. Proliferating Bergmann's glia replaced the Purkinje cell layer, and were diffusely scattered throughout the thinned molecular layer. The cerebellar white matter was pale, vacuolated, and infiltrated by numerous macrophages that were most concentrated in the core of folia, deep whites matter, and adjacent to the dentate nucleus. The macrophages contained myelin debris that stained blue with luxolfast-blue (LFB). The white matter demonstrated loss of myelin and axons on LFB and Bodian's stain. Similarly, theo superior cerebellar peduncle (SCP) and the dentatorubro thalamic tract from the dentate hilum to the ventral thalamus displayed degeneration of axons and myelin associated with lipid-laden macrophages, characteristic of active Wallerian degeneration (fig c \& d). The fibre tract degeneration was not present in other myelinated pathways and the cerebral white matter was free of similar degeneration.

The cerebral cortex, basal ganglia, and hippocampus were free of anoxic-ischaemic changes. Neither dark shrunken neurons nor neuronal loss were seen in any of the areas. Serial sections of hypothalamus taken at $3 \mathrm{~mm}$ intervals from the olfactory trigone to the level of pulvinar were free of significant changes. The spinal cord was also unremarkable.

The cerebrum, brainstem, and cerebellum had scattered microabscesses of various ages in which rare yeasts with pseudohyphae consistent with candida were demonstrated.

The muscles (deltoid and pectoralis major) were histologically abnormal. Randomly scattered atrophic fibres were focally surrounded by increased endomysial connective tissue. Enzyme histochemical preparations performed on frozen sections identified the atrophic fibres to be predominantly type II.

\section{Discussion}

Neuroleptic malignant syndrome (NMS), a rare complication of neuroleptic treatment, is fatal in up to $22 \%$ of cases. $^{2}$ Hyperpyrexia to a toxic degree (over 


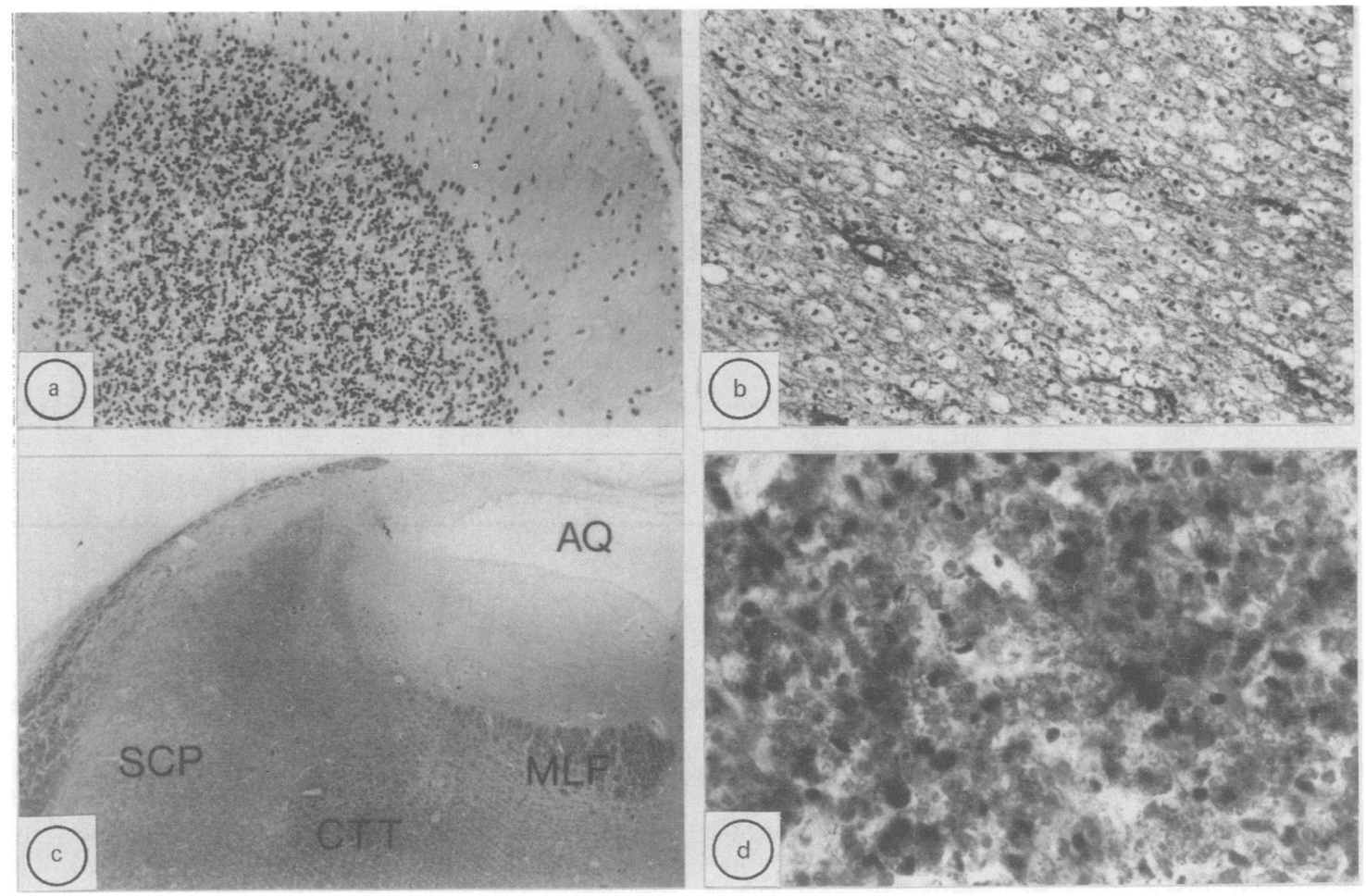

Figure (a) The cerebellar cortex shows extensive loss of Purkinje cells and proliferation of Bergmann's glia. Moderate loss of neurons and gliosis is present in the internal granular layer and in the molecular layer. H\&E ( $\times 90)$. (b) Macrophages laden with myelin debris in the cerebellar white matter that also shows loss of fibres and vacuolation is indicative of active Wallerian degeneration secondary to cerebellar cortical degeneration. Luxol-fast-blue stain $(\times 225)$. (c) The superior cerebellar peduncle (SCP) at the level of caudal midbrain is pale and depleted of myelinated fibres, in contrast to well-myelinated fibre tracts (medial longitudinal fasciculus: $M L F$ and central tegmental tract: CTT). AQ: aqueduct of Sylvius. Luxol-fast-blue stain $(\times 9)$. (d) Numerous lipid-laden macrophages are present in the dentatorubrothalamic pathway in this section from rostral midbrain. Oil-red-O $(\times 360)$.

$40^{\circ} \mathrm{C}$ ) has been recorded in about a third of patients with NMS in one series. ${ }^{2}$ Neuropathological studies have been few, and to our knowledge, no cases similar to ours have previously been reported.

The present patient suffered schizophrenia for many years and had received multiple neuroleptics including several phenothiazines and haloperidol, a butyrophenone. Both groups are implicated in inducing NMS, the latter with a higher frequency. Our patient had additionally been maintained on tetrabenazine, a dopamine blocking and depleting agent used to treat movement disorders. Tetrabenazine has also been shown to cause NMS. ${ }^{8}$ The NMS in our patient developed soon after the neuroleptic dose was increased, a previously reported pattern. ${ }^{2}$

Neuroleptic drugs predispose to hyperpyrexia by their anticholinergic properties, which block sweating and heat dissipation, and by their antidopaminergic properties, which interfere with hypothalamic thermoregulation..$^{-11}$ When an abrupt catastrophic disorder associated with hyperpyrexia occurs in a patient taking neuroleptics, the clinician must distinguish heat stroke from NMS. Neuroleptic-induced heat stroke can be differentiated from NMS by the absence of extrapyramidal signs, absence of diaphoresis, and a history of physical exercise or exposure to high ambient temperature. ${ }^{2}$ A permanent cerebellar syndrome has been reported in a patient with neuroleptic-induced heat stroke, ${ }^{9}$ but a pathological correlate was not described.

Most patients who develop NMS survive without complications. Reported fatalities have usually occurred in the acute stages, within hours or days. ${ }^{2}$ Our patient had an unusually long ( $4 \frac{1}{2}$ month) survival following NMS, resulting in unique and dramatic pathologic alterations in the brain. This case represents the longest survival of heat-induced CNS injury to be studied at postmortem examination. In the 
Table Cerebellar degeneration in hyperpyrexia

\begin{tabular}{|c|c|c|c|c|}
\hline Author(s) & Aetiology & $\begin{array}{l}\text { * Numbers of } \\
\text { cases }\end{array}$ & Clinical signs & $\begin{array}{l}\text { Purkinje cell } \\
\text { degeneration }\end{array}$ \\
\hline 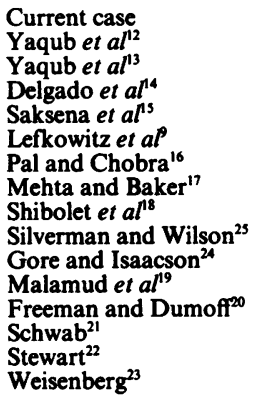 & $\begin{array}{l}\text { NMS } \\
\text { Heat stroke } \\
\text { Heat stroke } \\
\text { Heat stroke } \\
\text { Heat stroke } \\
\text { Heat stroke } \\
\text { Heat stroke } \\
\text { Heat stroke } \\
\text { Heat stroke } \\
\text { Thyroidectomy } \\
\text { Fever therapy } \\
\text { Heat stroke } \\
\text { Heat stroke } \\
\text { Heat stroke (Animals) } \\
\text { Heat stroke } \\
\text { Heat stroke }\end{array}$ & $\begin{array}{r}1 \\
1 \\
1 \\
1 \\
1 \\
1 \\
41 \\
1 \\
4 \\
1 \\
17 \\
125 \\
2 \\
\text { NA } \\
1 \\
1\end{array}$ & $\begin{array}{l}\text { Not Elicited } \\
\text { Pancerebellar syndrome (atrophy on CT) } \\
\text { Cerebellar ataxia } \\
\text { Lower motor neuron and anhidrosis } \\
\text { Pancerebellar syndrome } \\
\text { Pancerebellar syndrome } \\
\text { NA } \\
\text { Cerebellar, upper and lower motor neuron } \\
\text { NA } \\
\text { Pancerebellar syndrome } \\
\text { NA } \\
\text { NA } \\
\text { Pancerebellar syndrome } \\
\text { NA } \\
\text { Pancerebellar syndrome } \\
\text { Cerebellar ataxia, aphasia, and motor }\end{array}$ & $\begin{array}{l}+ \\
\text { NA } \\
+ \\
+ \\
\text { NA } \\
\text { NA } \\
+ \\
\text { NA } \\
+ \\
\text { NA } \\
+ \\
+ \\
+ \\
+ \\
\text { NA } \\
\text { NA }\end{array}$ \\
\hline
\end{tabular}

NA: Not Available.

* Numbers of cases showing clinical and/or pathologic cerebellar damage.

present case neuronal loss was marked in the cerebellum but not found in the cerebral cortex, basal ganglia, or hippocampus indicating selective vulnerability of cerebellar neurons to heat-induced injury.

It is clear from the previous studies that cerebellar deficits, either transient or permanently disabling, are characteristic of heat-induced CNS injury, whether due to heat stroke, ${ }^{912-23}$ fever therapy, ${ }^{24}$ or postsurgical (thyroidectomy) complications. ${ }^{25}$ To our knowledge, no cerebellar complications have been previously reported in patients surviving NMS or MH. The details of the relevant literature including pathologic studies of heat-induced CNS changes are summarised in the table.

In neuropathological studies of hyperpyrexia, ${ }^{161924}$ the most common CNS abnormalities were oedema, congestion, and haemorrhages, particularly in the vicinity of third and fourth ventricles, and in the white matter. It was felt that these non-specific alterations were related to terminal shock or circulatory collapse that accompanied hyperpyrexia, since the severity and distribution of these lesions were similar to the changes in shock not associated with hyperpyrexia.

The parenchymal injury due to hyperpyrexia per se was most striking and constant in the cerebellum. In those cases where death occurred after more than a week, the Purkinje cells were almost entirely lost, and the neurons of the deep cerebellar nuclei were also injured. With shorter survivals, however, the Purkinje cell changes were more subtle, consisting of neuronal swelling, pyknosis, or focal drop out. Interestingly, the cerebral cortex and basal ganglia were less frequently and only focally involved. This is in contrast to hypoxic CNS injury, in which selective vulnerability is shared among neurons in different regions of the brain including cerebral cortex, hippocampal Sommer's sector, cerebellum, and basal ganglia. ${ }^{26}$

The physical and biochemical properties that are the basis of this selective vulnerability of cerebellar neurons to heat-induced injuries are not completely known. It has been shown, however, that preferential degeneration of cerebellar neurons can be induced by heat stress in animals. ${ }^{21}$ It has also been shown that certain cells, such as established cancer cell lines, differ in their expression of heat shock protein during heat stress $^{27}$ implying that response to heat stress is to some extent a function of cell type. Recent in situ hybridisa tion studies of heat shock protein expression in the brains of rabbits have demonstrated heat shock geneinduction in the cerebellar neurons, in the absence of similar changes in neurons of other parts of the brain. ${ }^{28}$ This would further indicate that cerebellar neurons are unique in their response to heat stress.

\section{References}

1 Delay J, Deniker P. Drug-induced extrapyramidal syndrome. In Vinken PJ, Bruyn GW, eds. Handbook of Clinical Neurology Disease of the Basal Ganglia, vol 6. New York: Elsevier/North Holland, 1968:248-66.

2 Addonizio G, Susman VL, Roth SD. Neuroleptic malignant syndrome: review and analysis of 115 cases. Biol Psychiatry 1987;22:1004-20.

3 Araki M, Takagi A, Higuchi I, Sugita H. Neuroleptic malignan syndrome: caffeine contracture of single muscle fibers and muscle pathology. Neurology 1988;38:297-301.

4 Downey GP, Caroff S, Beck S, et al. Neuroleptic malignant syndrome: patient with unique clinical and physiological features. Am J Med 1984;77:338-40.

5 Horn E, Lach B, Lapierre Y, Hrdina P. Hypothalamic pathology in the neuroleptic malignant syndrome. Am J Psychiatry 1988;145:617-20.

6 Morris HH, McCormick WF, Reinarz JA. Neuroleptic malignan syndrome. Arch Neurol 1980;37:462-3.

7 Henderson VW, Wooten GF. Neuroleptic malignant syndrome: pathogenetic role for dopamine receptor blockade? Neurology 
1081;31:132-7.

8 Burke RE, Fahn S, Mayeux R, Weinberg H, Louis K, Willner JH. Neuroleptic malignant syndrome caused by dopamine-depleting drugs in a patient with Huntington disease. Neurology 1981;31:1022-6.

9 Lefkowitz D, Ford CS, Rich C, Biller J, McHenry LC Jr. Cerebellar syndrome following neuroleptic induced heat stroke. J Neurol Neurosurg Psychiatry 1983;46:183-5.

10 Zelman S, Guillan R. Heat stroke in phenothiazine-treated patients: a report of three fatalities. Am J Psychiatry 1970; 126:1787-90.

11 Reis J, Felten P, Rumbach L, Collard M. Hyperthermia with acute rhabdomyolysis in a psychotic treated with neuroleptics. Rev Neurol (Paris) 1983;139:595-6.

12 Yaqub BA, Daif AK, Papayiotopoulos CP. Pancerebellar syndrome in heat stroke: clinical course and CT scan findings. Neuroradiology 1987;29:294-6.

13 Yaqub BA, Al-Harthi SS, Al-Orainey IO, Laajam MA, Obeid MT. Heat stroke at the Mekka pilgrimage: clinical characteristics and course of 30 patients. $Q J$ Med 1986;59:523-30.

14 Delgado G, Tunon T, Gallego J, Villanueva JA. Spinal cord lesions in heat stroke. $J$ Neurol Neurosurg Psychiatry 1985; 48:1065-7.

15 Saksena HC, Dhamija JP, Chajer KS. Cerebellar ataxia-a complication of heat stroke. [letter] $J$ Assoc Physicians India 1985;33:5'

$16 \mathrm{Pal} \mathrm{AK,}$ 1973;21

17 Mehta AC, Banu ^B. Persistent neurologic deficits in ?
Neurology 1970;20:336-40.

18 Shibolet S, Coll R, Gilat T, Sohar E. Heatstroke: its clinical picture and mechanism in 36 cases. $Q \mathrm{~J}$ Med 1967;36:525-48.

19 Malamud N, Haymaker W, Custer RP. Heat stroke: a clinicopathologic study of 125 fatal cases. Military Surgeon 1946; 99:397-449.

20 Freeman W, Dumoff E. Cerebellar syndrome following heat stroke. Arch Neurol Psychiatry 1944;51:67-72.

21 Schwab W. Brain changes in sunstroke. JAMA 1925;84:712.

22 Stewart RM. On the occurrence of a cerebellar syndrome following heat stroke. Rev Neurol Psychiatry 1918;16:78-93.

23 Weisenberg TH. Nervous symptoms following sunstroke. JAMA 1912;58:2015-7.

24 Gore I, Isaacson NH. The pathology of hyperpyrexia: observation at autopsy in 17 cases of fever therapy. Am J Pathol 1949; 25:1029-59.

25 Silverman JJ, Wilson JE. An unusual complication following thyroidectomy: heat stroke with permanent cerebellar damage. Ann Int Med 1950;33:1036-41.

26 Norenberg MD, Gregorios JB. Central nervous system manifestations of systemic disease. In: Davis RL, Robertson DM, eds. Textbook of Neuropathology. Baltimore: Williams \& Wilkins, 1985:403-67.

27 Richter WW, Issinger OG. Differential heat shock response of primary human cell cultures and established cell lines. Biochem Biophys Res Commun 1986;141:46-52.

$\checkmark$, Brown IR. Selective induction of a heat shock gene in nd cerebellar neurons of the rabbit brain detected disation. Mol Brain Res 1987;3:89-93. 